\title{
The growing impact of Acta Gastro-Enterologica Belgica
}

\author{
T. Vanuytsel ${ }^{1-2}$, N. Lanthier ${ }^{3-4}$ \\ (1) Gastroenterology and Hepatology, University Hospitals Leuven, KU Leuven, Leuven, Belgium ; (2) Translational Research in Gastrointestinal Diseases (TARGID), KU \\ Leuven, Leuven, Belgium ; (3) Service d'Hépato-gastroentérologie, Cliniques universitaires Saint-Luc, UCLouvain, Brussels, Belgium; (4) Laboratory of Gastroenterology
} and Hepatology, Institut de Recherche Expérimentale et Clinique, UCLouvain, Brussels, Belgium.

Keywords : Belgian week of gastroenterology, Brohée prize, hemorrhoids, hepatopulmonary syndrome.

Each year, the launch of the first edition of the Acta Gastro-Enterologica Belgica is a special occasion. Traditionally, all accepted abstracts of the Belgian Week of Gastroenterology are published in our journal and the printed edition is handed out to all the attendees of the meeting. Moreover, it is always a pleasure to meet and interact with our colleagues and readers during these exciting three days filled with the latest advances in clinical and scientific aspects of gastroenterology.

However, after a successful edition of the conference just before the start of the lockdown in March 2020 due to the COVID-19 pandemic, everything changed in the past year and will continue to be impacted at least during the first half of 2021 (1-3). Because of the containment measures, this year's Belgian Week of Gastroenterology will be the first digital, online edition. Nevertheless, it is a pleasure to see that many of you still submitted your finest scientific and clinical work in the form of an abstract, which again underlines the enthusiasm and quality of Belgian gastroenterology, including gastroenterologists, scientists, nursing staff and other paramedics. Even if we will not be able to meet you in person at the booth of our journal, we will stick to the yearly tradition of providing our journal with all the published abstracts to all of those who registered for the meeting and all the members of the SRBGE and VVGE.

During this edition Belgian Week of Gastroenterology we also honor another tradition: the award for the best original manuscript published in our journal in the previous year, based on the votes of all the members of our editorial board. This year's prize is awarded to Dr. Reenaers (Centre Hospitalier Universitaire de Liège) and colleagues for their manuscript "Effectiveness and persistence of Vedolizumab in patients with inflammatory bowel disease: results from the Belgian REal-LIfe study with VEdolizumab (Be-RELIVE)" (4). In this retrospective collaborative study from 15 Belgian IBD centers, the effectiveness and continuation of treatment with vedolizumab, was described. However, based on feedback from our readers, it is clear that many of you also value the high-quality reviews, often with a clear impact on daily clinical practice. This is why we created an additional prize for the best review published last year in our journal. The first best review prize is awarded to Dr. Dano (Cliniques universitaires Saint-Luc) and colleagues for their review "Guidelines for an optimal management of a malignant colorectal polyp. What is essential in a pathology report?" (5). Also this work is a joint effort of multiple Belgian centers demonstrating the collaborative spirit in Belgian gastroenterology which we foster as a journal. We hope that these two annual rewards form an additional stimulus to keep sending us your best work in the coming years.

Acta Gastro-Enterologica Belgica is attracting more and more attention over the past years. Since the start of our open-access policy early 2020 (6), which allows the readers to directly read or download all published articles from our website or via Pubmed, an increasing number of manuscripts are being accessed. In the first month we had 624 hits which has increased to more than 2500 hits per month at the end of the year, which is a great success and will continue to increase the visibility of the publications and the appeal of our journal to authors. Indeed, together with the number of reads, also the submissions continue to rise. This year was an absolute record with 542 submissions which is a $60 \%$ increase compared to 2019. The increasing number of submissions will allow us to only select the best manuscripts for publication in an ongoing effort to provide the best quality to our readers. We also want to use this occasion to thank all our associate editors and Mrs. Mia Persoons from the editorial office for their continued effort in reviewing and processing all the submissions.

Also in this edition of the journal you will find a selection of high-quality articles. We would especially like to recommend the Belgian consensus guidelines on the management of hemorrhoidal disease by Dr. De Schepper (Universitair Ziekenhuis Antwerpen) and colleagues with clear recommendations for clinical practice (7) and the state-of-the-art review by Dr. Raevens (Ghent University) on recent advances in the approach to hepatopulmonary syndrome and portopulmonary hypertension (8), which was awarded the biennial

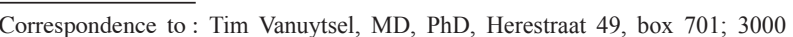
Leuven, Belgium

E-mail : tim.vanuytsel@uzleuven.be

Submission date : 25/01/2021

Acceptance date : 25/01/2021
} 
Georges Brohée prize for the best Belgian research in the field of gastroenterology (9).

We wish you a pleasant reading!

\section{References}

1. LANTHIER N.,VANUYTSEL T. The changing landscape of hepatology and gastroenterology. Acta Gastroenterol Belg., 2020, 83(3) : 371-372.

2. SINONQUEL P., AERTS M., BADAOUI A., BISSCHOPS R., BLERO D., DEMEDTS I., et al. BSGIE survey on COVID-19 and gastrointestinal endoscopy in Belgium : results and recommendations. Acta Gastroenterol Belg., 2020, 83(2) : 344-354.

3. DAHLQVIST G., CICCARELLI O., VAN VLIERBERGHE H., BERREVOET F., VANWOLLEGHEM T., YSEBAERT D., et al. Liver transplantation during the COVID-19 epidemic : recommendations from the Belgian Liver Intestine Transplant Committee (BeLIAC). Acta Gastroenterol Belg., 2020, 83(2) : 340343

4. REENAERS C., CREMER A., DEWIT O., DE VROEY B., VAN MOERKERCKE W., BOSSUYT P., et al. Effectiveness and persistence of
Vedolizumab in patients with inflammatory bowel disease : results from the Belgian REal-LIfe study with VEdolizumab (Be-RELIVE). Acta Gastroenterol Belg., 2020, 83(1) :15-23.

5. DANO H., BALDIN P., DEMETTER P., DRIESSEN A., HOORENS A. SAGAERT X., et al. Guidelines for an optimal management of a malignant colorectal polyp. What is essential in a pathology report ? Acta Gastroenterol Belg., 2020, 83(1) : 53-59.

6. LANTHIER N.,VANUYTSEL T. For better visibility of Acta GastroEnterologica Belgica. Acta Gastroenterol Belg., 2020, 83(2) : 243-244.

7. DE SCHEPPER H., COREMANS G., DENIS M., DEWINT P., DUINSLAEGER M., GIJSEN I., et al. Belgian consensus guideline on the management of hemorrhoidal disease. Acta Gastroenterol Belg., 2021, 84(1) : 101120.

8. RAEVENS S., GEERTS A., DEVISSCHER L., VAN VLIERBERGHE H., VAN STEENKISTE C.,COLLE I. Recent advances in the approach to hepatopulmonary syndrome and portopulmonary hypertension. Acta Gastroenterol Belg., 2021, 84(1) : 95-99.

9. BORBATH I., FIASSE R.,VAN HOOTEGEM P. The "Fonds Georges Brohée": a longstanding Belgian national initiative to stimulate research in hepatogastroenterology. Acta Gastroenterol Belg., 2021, 84(1) : 91-94. 